\title{
Correspondence:
}

\section{The prevalence of $A_{2}$ and $A_{2} B$ subgroups in blood donors at a tertiary care teaching hospital blood bank of Rayalaseema region: a pilot study}

Polymorphisms in the genes coding for $A$ gene leads to subgroups of A. No published data regarding the prevalence of subgroups of A blood group in Andhra Pradesh, India is available. The importance of subgrouping is that the $\mathrm{A}$ antigens in various subgroups may differ both quantitatively and qualitatively ${ }^{1}$. Some individuals with blood groups $A_{2}, A_{3}, A_{x}, A_{\text {el }}, A_{\text {end }}, A_{2} B$ etc., have anti- $\mathrm{A}_{1}$ antibodies and may present problems in blood grouping.

At our center, the typing of A subgroup of all blood donors was done using commercial anti $\mathrm{A}_{1}$ lectin, anti- $\mathrm{A}$ and anti- $\mathrm{AB}$ antisera as per the manufacturer's instructions. On analysis of a total of 5,505 blood groupings over a period of one year, 1,486(27\%) individuals had A antigen. Of these, 1,137 (20.7\%) were typed as A group and 349 (6.3\%) as $\mathrm{AB}$ group based on the presence of associated $\mathrm{B}$ antigen. Of the 1,137 A group individuals, $1,090(95.9 \%)$ had $\mathrm{A}_{1}$ antigen (subgroup $A_{1}$ ) and the rest $47(4.1 \%$ ) had no detectable $A_{1}$ antigen (subgroup $A_{2}$ ). Similarly among the $349 \mathrm{AB}$ group individuals, 282(80.8\%) had $\mathrm{A}_{1}$ antigen (subgroup $\mathrm{A}_{1} \mathrm{~B}$ ) and $67(19.2 \%$ ) had no detectable $A_{1}$ antigen (subgroup $A_{2} B$ ). The number of individuals who lack $A_{1}$ antigen is less among $\mathrm{A}$ group individuals in contrast to $A B$ group individuals and this difference was found to be statistically significant $(\mathrm{p}<0.0001)$. This may be due to the recessive nature of $A_{2}$ gene compared to $A_{1}$ gene and requirement of a single $A_{2}$ gene and a $B$ gene to develop as $\mathrm{A}_{2} \mathrm{~B}$ blood group phenotypically and two $A_{2}$ genes or one $A_{2}$ gene and one $O$ gene to develop as $\mathrm{A}_{2}$ blood group. Some postulate the presence of a strong $B$ gene that would suppress $A_{1}$ antigen activity. ${ }^{2}$ No other subgroups of A could be detected in the present study due to the small number of donors phenotyped for subgroups of A. Similar results were obtained in other studies from Karnataka ${ }^{3}$ and Japan. ${ }^{4}$ By including a much larger population, the frequency of other A subgroup antigens can also be estimated. In the present study, the prevalence of $\mathrm{A}_{2}$ and $\mathrm{A}_{2} \mathrm{~B}$ sub groups was found to be 0.85 percent and $1.21 \%$ in blood donors respectively.

\section{REFERENCES}

1. Thakral B, Saluja K, Bajpai M, Sharma RR, Marwaha $\mathrm{N}$. Importance of weak ABO subgroups. Lab Med 2005;36:32-4.

2. Voak D, Lodge TW, Reed JV. A possible explanation for the expression of $\mathrm{A}_{2} \mathrm{~B}$ phenotypes observed in some populations. Vox Sang 1970;18:471-4.

3. Shastry $S$, Bhat $S$. Imbalance in $A_{2}$ and $A_{2} B$ phenotype frequency of $\mathrm{ABO}$ group in South India. Blood Transfus 2010;8:267-70.

4. Ogasawara K,Yabe R, Uchikawa M, Saitou N, Bannai M, Nakata K, et al. Different alleles cause an imbalance in $\mathrm{A}_{2}$ and $\mathrm{A}_{2} \mathrm{~B}$ phenotypes of the $\mathrm{ABO}$ blood group. Vox Sang 1998;74:242-7.

I.S. Chaitanya Kumar, A. Yashovardhan, B. Suresh Babu, Anju Verma, K.V. Sreedhar Babu, DS Jothi Bai. Department of Immuno Haematology and Blood transfsion, Sri Venkateswara Institute of Medical Sciences, Tirupati. 